\title{
ESTUDO COMPARATIVO DOS EFEITOS DA TALIDOMIDA, DA CICLOSPORINA E DO DICLOFENACO NA SOBREVIDA DE ALOENXERTOS CUTÂNEOS EM COELHO
}

\author{
Diva Novy Barbosa Chaves, luiz Ronaldo Alberti, Andy Petroianu* \\ Trabalho realizado pelo Departamento de Cirurgia da Faculdade de Medicina da Universidade Federal de Minas Gerais, Belo Horizonte, MG
}

\author{
*Correspondência: \\ Av. Afonso Pena, n 1626, \\ Apto 1901 \\ Belo Horizonte/MG \\ CEP: $30130-005$ \\ Tel./Fax: (31) 3274-7744 \\ petroian@medicina.ufmg.br
}

\begin{abstract}
RESUMO
Oвjetivo. Verificar se a talidomida é capaz de evitar a rejeição de aloenxertos de pele em coelhos, como droga isolada, ou melhorar a eficácia de doses subterapêuticas de ciclosporina, comparando seu efeito ao de doses terapêuticas da ciclosporina e também ao papel antiinflamatório do diclofenaco de sódio.
\end{abstract}

Métodos. Foram estudados 42 coelhos, distribuídos nos seguintes grupos ( $n=6)$ : Grupo I - controle com auto-enxerto; Grupo 2 - controle com aloenxerto; Grupo 3 - aloenxerto sob o efeito de talidomida ( $100 \mathrm{mg} / \mathrm{kg} / \mathrm{dia}$ ); Grupo 4 - aloenxerto sob o efeito de diclofenaco de sódio (2 mg/kg/dia); Grupo 5 - aloenxerto sob o efeito de ciclosporina ( $10 \mathrm{mg} / \mathrm{kg} / \mathrm{dia}) ;$ Grupo 6 - aloenxerto sob o efeito de ciclosporina (5 mg/kg/dia); Grupo 7 - aloenxerto sob o efeito de ciclosporina (5 mg/kg/dia) associada a talidomida (100 mg/kg/dia). Foram retirados enxertos circulares de pele total do dorso de uma das orelhas do animal. Os medicamentos foram administrados por cateter orogástrico, a partir do dia anterior ao transplante. Os enxertos foram trocados entre coelhos de raças diferentes.

Resultados. A ciclosporina a $10 \mathrm{mg} / \mathrm{kg} / \mathrm{dia}$ prolongou a sobrevida dos enxertos de pele, sendo seu efeito comparável ao obtido com a ciclosporina em dose subterapêutica (5 mg/kg/dia) associada a talidomida a $100 \mathrm{mg} / \mathrm{kg} / \mathrm{dia}$. A talidomida isoladamente, mesmo em concentração de $100 \mathrm{mg} / \mathrm{kg} / \mathrm{dia}$, e o diclofenaco tiveram efeito mínimo na sobrevida média dos aloenxertos cutâneos. O número de eosinófilos no infiltrado inflamatório circunjacente à necrose foi maior nos grupos tratados com diclofenaco e com ciclosporina a $5 \mathrm{mg} / \mathrm{kg} / \mathrm{dia}$ e menor no grupo em que se associou ciclosporina com talidomida. Conclusão. A talidomida pode ser uma droga útil para associar-se a baixas doses de ciclosporina no tratamento de aloenxertos cutâneos.

Unitermos: Talidomida. Ciclosporina. Diclofenaco sódico. Enxerto de pele. Sobrevida. Aloenxerto cutâneo.

\section{INTRODUÇÃO}

A cobertura da superfície corpórea no menor prazo possível é fundamental para a sobrevida de pacientes com queimaduras extensas ${ }^{1,2}$. Nos casos mais graves, o paciente não possui áreas doadoras de pele suficientes para a auto-enxertia. Entre as alternativas terapêuticas para solucionar esta situação, destaca-se a utilização de transplantes homógenos de pele. $\mathrm{O}$ aloenxerto tem sido considerado como a melhor alternativa de transplante cutâneo, por suas qualidades biológicas e disponibilidade nos bancos de pele $e^{3}$. O desenvolvimento vascular ocorre nos aloenxertos de forma semelhante à dos auto-enxertos, entretanto a resposta imunitária leva à rejeição destes transplantes em prazo geralmente inferior a vinte dias" ${ }^{4}$.

Diversos estudos experimentais e clínicos em grandes queimados mostraram que drogas imunossupressoras são capazes de prolongar a sobrevida dos aloenxertos cutâneos até que ocorra a recuperação de áreas doadoras ${ }^{4,5}$.

Entre os imunossupressores, a ciclosporina, descoberta na década de 1970, foi um marco na obtenção de imunodepressão clínica. Atualmente, este medicamento pertence à primeira linha terapêutica em transplantes. Estudos experimentais seguidos de investigações clínicas comprovaram sua eficácia na sobrevida de aloenxertos cutâneos ${ }^{6}$.

Por outro lado, a ciclosporina apresenta diversos efeitos colaterais, tais como nefrotoxicidade, hepatotoxicidade, hiperplasia gengival, convulsões, hipertricose, osteoporose, infecções, oncogenicidade e outras complicações dose-dependentes? ${ }^{7}$. Além disso, a ciclosporina é um medicamento de alto custo. Para reduzir a toxicidade da ciclosporina sem interferir na rejeição de aloenxertos, têm sido feitas tentativas com doses subterapêuticas, associando essa droga a outros medicamentos, como corticóides e antiinflamatórios. Todavia, esses fármacos também apresentam efeitos colaterais. Outros agentes imunossupressores ou que possam ser associados aos já existentes para reduzir a toxicidade são continuamente pesquisados ${ }^{8}$.

Nesta linha de investigações em transplantes de tecidos, observouse a partir de 1989 que a talidomida associada a doses subterapêuticas de ciclosporina é tão efetiva quanto a ciclosporina em doses terapêuticas no controle da rejeição e no aumento da sobrevida de transplantes cardíacos heterotópicos em coelhos ${ }^{9}$. Resultados semelhantes a esta associação foram obtidos por Vogelsang et al. (1988) em transplantes de medula óssea em ratos ${ }^{10}$. Por seu mecanismo de ação diferente de 
muitos outros imunossupressores, a talidomida oferece a possibilidade de tratamento combinado com outros agentes, sem a superposição de suas toxicidades.

As propriedades imunodepressoras da talidomida já foram documentadas em diversas condições auto-imunes e inflamatórias. Seu uso foi, inclusive, autorizado em casos de reação do enxertocontra-hospedeiro em transplantes de medula óssea no Brasil. Contudo, a sua utilização em trabalhos experimentais com enxertos homógenos de pele mostrou resultados controversos ". Por seu custo reduzido e baixa toxicidade, é possível que a talidomida seja uma opção para aumentar a eficácia imunodepressora em aloenxertos de pele, quando associada a doses menores de ciclosporina, reduzindo os efeitos adversos deste medicamento.

Os corticosteróides, que além de imunossupressores apresentam um importante efeito antiinflamatório, têm sido associados a outros imunossupressores na doença do enxerto-contra-hospedeiro' ${ }^{12}$. Apesar de se conhecer o efeito benéfico dos antiinflamatórios nos resultados de aloenxertos, o estudo destes medicamentos isoladamente em transplante de tecidos ainda é muito restrito. Entre as drogas antiinflamatórias, o diclofenaco é conhecido por sua potência terapêutica, mesmo não havendo relatos a respeito de seu efeito como droga isolada em presença de aloenxertos cutâneos.

O objetivo do presente trabalho foi verificar se a talidomida é capaz de evitar a rejeição de aloenxertos de pele em coelhos, como droga isolada, ou melhorar a eficácia de doses subterapêuticas de ciclosporina. Para compreender melhor sua ação imunodepressora ou antiinflamatória, comparou-se seu efeito ao de doses terapêuticas da ciclosporina e também ao papel antiinflamatório do diclofenaco de sódio.

\section{Métodos}

Esta pesquisa foi aprovada pelo Comitê de Ética em Experimentação Animal (CETEA/UFMG). Todos os procedimentos envolvendo os animais seguiram os preceitos estabelecidos no Código Brasileiro de Experimentação Animal de $1988^{13}$.

Foram utilizados 42 coelhos (Oryctolagus cuniculus) do sexo masculino, de idades semelhantes (cerca de dois meses), sendo 21 da raça Califórnia e 21 da raça Nova Zelândia Branco. Eles foram acomodados em gaiolas individuais no biotério, recebendo ração comercial específica e água ad libitum durante todo o período do experimento. $O$ peso dos animais variou entre 1,6 e 2,4 kg, sendo a média de 1,9 \pm 0,2 kg.

Os coelhos foram distribuídos em sete grupos de seis animais, sendo três de cada raça: Grupo I $(n=6)$ : controle com auto-enxerto; Grupo 2 ( $n=6$ ): controle com aloenxerto; Grupo $3(n=6)$ : aloenxerto sob efeito de talidomida na dose de $100 \mathrm{mg} / \mathrm{kg} / \mathrm{dia}$; Grupo $4(\mathrm{n}=6)$ : aloenxerto sob efeito de diclofenaco na dose de $2 \mathrm{mg} / \mathrm{kg} / \mathrm{dia}$; Grupo $5(n=6)$ : aloenxerto sob efeito de ciclosporina na dose de 10 $\mathrm{mg} / \mathrm{kg} / \mathrm{dia}$; Grupo $6(\mathrm{n}=6)$ : aloenxerto sob efeito de ciclosporina na dose de $5 \mathrm{mg} / \mathrm{kg} / \mathrm{dia}$; Grupo 7 ( $\mathrm{n}=6$ ): aloenxerto sob efeito de ciclosporina, na dose de $5 \mathrm{mg} / \mathrm{kg} / \mathrm{dia}$, associada a talidomida na dose de $100 \mathrm{mg} / \mathrm{kg} / \mathrm{dia}$.

Os aloenxertos foram trocados entre um coelho Califórnia e um coelho Nova Zelândia Branco, de forma que cada animal foi doador e ao mesmo tempo receptor de enxerto.
Os medicamentos foram administrados por cateter orogástrico no dia anterior à operação, imediatamente antes de iniciar o ato cirúrgico e em todos os dias pós-operatórios do período de acompanhamento, no mesmo horário. Esse procedimento foi facilitado pelo uso de caixa de contenção para coelhos.

Os coelhos foram anestesiados com injeção intramuscular na região glútea, com cloridrato de quetamina a $5 \%$, na dose de $35 \mathrm{mg} / \mathrm{kg}(0,7 \mathrm{ml} /$ $\mathrm{kg})$, associado a cloridrato de xilazina a $2 \%$, na dose de $6 \mathrm{mg} / \mathrm{kg}(0,3 \mathrm{ml} /$ $\mathrm{kg})$ e a maleato de acepromazina a $1 \%$, na dose de $2 \mathrm{mg} / \mathrm{kg}(0,2 \mathrm{ml} / \mathrm{kg})$. Quando necessário, foi aplicada adicionalmente metade da dose inicial dos anestésicos. A anti-sepsia foi feita com solução de clorexidina a 2\%, após tonsura da orelha na área a ser operada.

O procedimento cirúrgico, com técnica asséptica, foi realizado em dois coelhos de raças diferentes, obedecendo as seguintes etapas:

- Foram colocados os campos cirúrgicos esterilizados com exposição da orelha;

- Procedeu-se a incisão para a retirada de um enxerto circular de pele total, com $2 \mathrm{~cm}$ de diâmetro, no dorso de uma das orelhas;

- Como de rotina nos enxertos de pele total, foi feito um desbaste da gordura hipodérmica no enxerto retirado e o mesmo foi colocado em solução de cloreto de sódio a 0,9\% em temperatura ambiente;

- A área doadora foi recoberta com gaze umedecida em solução salina a 0,9\%;

- Retirou-se o enxerto auricular do outro coelho, seguindo a mesma técnica;

- O enxerto retirado do segundo coelho foi fixado à área doadora do primeiro coelho e o enxerto retirado do primeiro coelho foi colocado na área doadora do segundo coelho, ambos com sutura contínua, utilizando fio de mononálon 5-0;

- Não foram feitos curativos.

Após a operação, os animais foram observados em suas gaiolas até a recuperação da anestesia.

No pós-operatório, os animais continuaram recebendo água e ração sem restrições e foram observados diariamente quanto ao seu estado geral e ao aspecto do enxerto, além de serem pesados semanalmente.

Para observar o aspecto de necrose total do aloenxerto ou após o trigésimo dia pós-operatório, o coelho era anestesiado com injeção intramuscular na região glútea, com cloridrato de quetamina a 5\% (35 $\mathrm{mg} / \mathrm{kg}$ ), cloridrato de xilazina a $2 \%(6 \mathrm{mg} / \mathrm{kg})$ e maleato de acepromazina a $1 \%(2 \mathrm{mg} / \mathrm{kg})$. Fragmentos incluindo o enxerto e a pele normal adjacente eram retirados para exame histológico. A avaliação da integração dos enxertos foi feita sob observação direta do animal e confirmada histologicamente, mediante análise do aspecto da pele transplantada e comparação com a pele adjacente ao enxerto. Comparou-se também o enxerto transplantado em animais tratados com os enxertos dos grupos-controle (auto-enxertos e aloenxertos sem imunossupressores). Os critérios para a rejeição foram 0 escurecimento do enxerto e o surgimento de úlceras em sua superfície, que evoluíram para isquemia com enrijecimento e necrose.

Os fragmentos de enxerto e pele íntegra adjacente, de cerca de 2 $\times 0,5 \mathrm{~cm}$ foram fixados em solução de formaldeído a $4 \%$ (formol a 10\%). Em seguida, foram preparados para inclusão em parafina. Estes cortes foram corados com hematoxilina e eosina (HE) e utilizados para análise histológica e avaliação do número de eosinófilos nos tecidos. 
Utilizando ocular reticulada e aumento de 400 vezes, quantificou-se o número de eosinófilos encontrados em cinco campos microscópicos consecutivos, de permeio ao exsudato inflamatório reacional, na área do leito receptor do enxerto.

Para comparar entre os grupos o peso inicial dos coelhos, o número de eosinófilos e o tempo decorrido entre o início da rejeição e a necrose total utilizou-se o teste de Kruskal-Wallis. Os tempos até o início da rejeição do tecido e a necrose total do enxerto foram analisados pelo método de Kaplan-Meier, que estima de forma não-paramétrica a sobrevida. As comparações entre os grupos foram feitas por meio do teste logrank. Os dados foram apresentados como média \pm desvio padrão da média. Todos os resultados foram considerados significativos para uma probabilidade de significância inferior a 5\% $(p<0,05)$.

\section{Resultados}

Todos os animais recuperaram-se espontaneamente da anestesia e apresentaram evolução pós-operatória sem intercorrências. Em relação ao peso inicial dos coelhos, não houve diferença entre os grupos $(p=0,806)$.

Houve diferenças entre os grupos quanto ao tempo entre a operação e a ocorrência dos primeiros sinais de rejeição ( $p<$ 0,0001 - teste de logrank). A rejeição foi mais rápida nos grupos 2 (controle com aloenxerto) e 6 (aloenxertos que receberam ciclosporina $5 \mathrm{mg} / \mathrm{kg} / \mathrm{dia}$ ). Os enxertos dos grupos 5 (aloenxertos que receberam ciclosporina a $10 \mathrm{mg} / \mathrm{kg} / \mathrm{dia}$ ) e 7 (que receberam ciclosporina $5 \mathrm{mg}$ e talidomida $100 \mathrm{mg}$ ) permaneceram viáveis por mais tempo, sem diferença entre si. Os resultados dos animais do Grupo I (controle com auto-enxerto) foram excluídos da análise estatística por não apresentarem o evento estudado (rejeição dos enxertos) até o trigésimo dia, sendo considerados dados censurados pelo método de Kaplan-Meier (Tabela I).

Em relação ao tempo entre a operação e a necrose total dos enxertos, nos coelhos do Grupo 5 (ciclosporina a $10 \mathrm{mg} / \mathrm{kg} / \mathrm{dia}$ ) permaneceram viáveis por mais tempo em relação aos demais grupos ( $17,7 \pm 8,6$ dias). A diferença não foi significativa somente quando comparada com a média do Grupo 7 (ciclosporina associada a talidomida), que foi 9,4 $\pm 2,7$ dias. Neste tempo, todos os animais do Grupo 2 (controle com aloenxerto) já haviam apresentado necrose, que ocorreu em 6,8 $\pm 1,3$ dias $(p<0,0001$ - teste de logrank) (Tabela I).

Os resultados dos animais do Grupo I (controle com autoenxerto) foram excluídos da análise estatística porque não apresentaram o evento estudado (necrose dos enxertos) até o trigésimo dia, sendo considerados dados censurados pelo método de KaplanMeier. O coelho número 2 do Grupo 7 foi também excluído da análise estatística, por ter sido encontrado morto no I3o dia após a operação, antes de apresentar necrose total do enxerto, sendo também considerado um dado censurado pelo método de KaplanMeier. Esse coelho ficou prostrado nos dias que antecederam sua morte, indicando que estava doente. A análise histológica do seu enxerto mostrou áreas de regeneração do epitélio transplantado. A necropsia não identificou a causa de sua morte.

\begin{tabular}{|c|c|c|c|}
\hline Grupos & Início rejeição ${ }^{*}$ & $\begin{array}{l}\text { Necrose total } \\
\text { enxerto" }\end{array}$ & $\begin{array}{c}\text { Entre início } \\
\text { rejeição e necrose } \\
\end{array}$ \\
\hline Aloenxerto & $4,7 \pm 0,8$ & $6,8 \pm 1,3$ & $2,2 \pm 1,5$ \\
\hline $\begin{array}{l}\text { Talidomida } \\
(100 \mathrm{mg} / \mathrm{kg} / \mathrm{dia})\end{array}$ & $5,8 \pm 0,4$ & $7,8 \pm 0,8$ & $2,0 \pm 0,9$ \\
\hline $\begin{array}{l}\text { Diclofenaco } \\
(2 \mathrm{mg} / \mathrm{kg} / \mathrm{dia})\end{array}$ & $5,3 \pm 0,5$ & $7,5 \pm 1,0$ & $2,2 \pm 1,0$ \\
\hline $\begin{array}{l}\text { Ciclosporina } \\
(10 \mathrm{mg} / \mathrm{kg} / \mathrm{dia})\end{array}$ & $11,5 \pm 4,6$ & $17,7 \pm 8,6$ & $6,2 \pm 5,0$ \\
\hline $\begin{array}{l}\text { Ciclosporina } \\
\text { (5mg/kg/dia) }\end{array}$ & $4,3 \pm 0,5$ & $9,0 \pm 3,7$ & $4,7 \pm 3,7$ \\
\hline
\end{tabular}

\section{Ciclosporina}

$(5 \mathrm{mg} / \mathrm{kg} / \mathrm{dia})+$

\section{Talidomida}

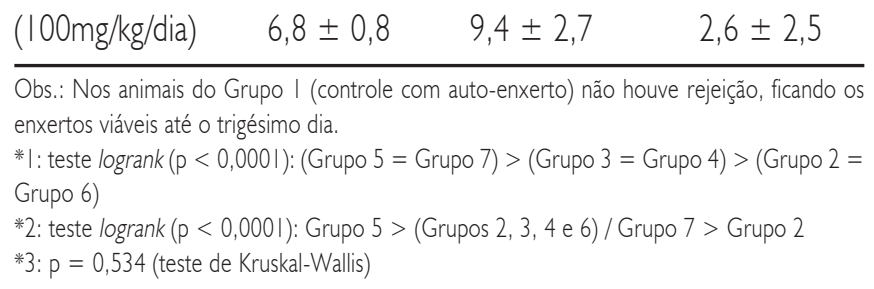

Observou-se ainda que nos animais dos grupos 2, 3 e 4, a rejeição iniciou com escurecimento do enxerto seguido de necrose em bloco, enquanto nos animais dos grupos 5, 6 e 7, foi mais comum o aparecimento de úlceras ou manchas escuras que confluíam progressivamente até a necrose total.

Dois animais do Grupo 5 (ciclosporina $10 \mathrm{mg} / \mathrm{kg} / \mathrm{dia}$ ) com sobrevidas de 25 e 30 dias apresentaram um padrão de necrose diferente, com induração e contração do enxerto, sem escurecimento, sugerindo a ocorrência de rejeição lenta.

Após o 29 dia pós-operatório, o coelho número 3 do Grupo 5 mostrava sinais de dermatose submandibular, que pode ser atribuída ao uso prolongado da ciclosporina. Não foram observados outros efeitos colaterais das drogas estudadas.

Quanto ao tempo decorrido entre o início da rejeição do tecido e a necrose total do enxerto, não foram constatadas diferenças entre os grupos $(p=0,534)$ (Tabela I).

Em relação à avaliação histológica, no Grupo I (controle com autoenxerto) o infiltrado inflamatório foi, em geral, mais escasso do que nos demais grupos. Em alguns casos, ocorreram poucos focos circunscritos de exsudato inflamatório ou grandes áreas de tecido do leito receptor sem infiltrado inflamatório significativo. Neste grupo, todos os animais, após 30 dias, apresentaram fibrose bem desenvolvida, com a morfologia de cicatrização normal.

Em todos os fragmentos obtidos da área de enxertos com necrose total (grupos 2 a 7), observou-se infiltrado inflamatório moderado a 


\section{Figura I - Comparação dos grupos de coelhos, quanto ao número de eosinófilos por $\mathrm{mm}^{2}$, no infiltrado inflamatório circunjacente ao aloenxerto necrosado}

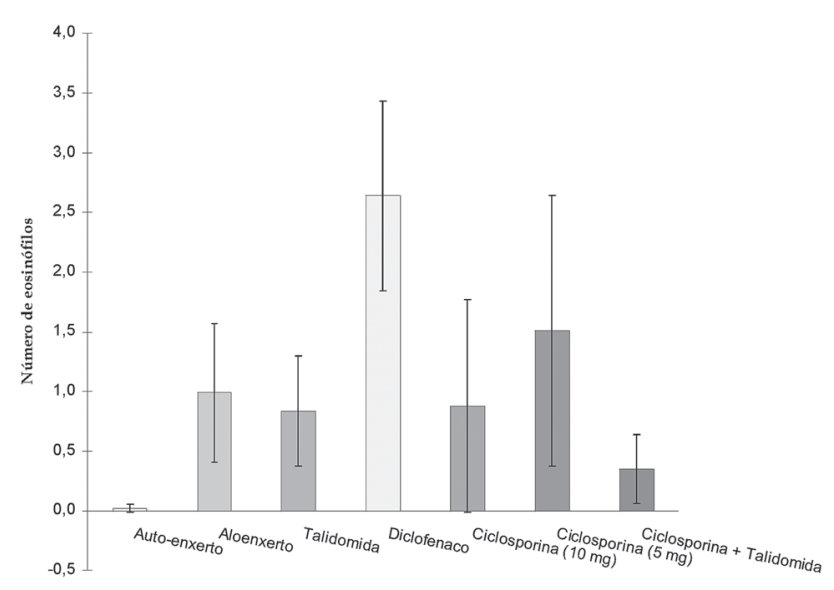

$\mathrm{P}=0,00 \mathrm{I}$ (teste Kruskal-Wallis)

Grupo 4 = Grupo $6>($ Grupos 2, 3 e 5) $>$ Grupo $7>$ Grupo I

intenso constituído por linfócitos, plasmócitos e polimorfonucleares, disperso em toda a derme e tecido subcutâneo do leito receptor, entremeado por focos hemorrágicos. No leito receptor e na derme da pele adjacente ao enxerto, foi encontrada neoformação fibrosa de intensidade variável, em todos os casos com mais de oito dias de sobrevida. Nos casos em que os enxertos tiveram sobrevida menor (quatro a sete dias), a fibrose foi menos desenvolvida.

Os grupos 4 (diclofenaco) e 6 (ciclosporina $5 \mathrm{mg} / \mathrm{kg} / \mathrm{dia}$ ) apresentaram maior quantidade de eosinófilos por $\mathrm{mm}^{2}$ na região do enxerto do que o encontrado nos demais grupos. Já no Grupo 7 (ciclosporina associada a talidomida) foi encontrada a menor eosinofilia tecidual de todos os grupos, exceto o Grupo I (controle com auto-enxerto) (Figura I).

\section{Discussão}

As pesquisas com talidomida iniciaram em 1987, seguindo uma linha de pesquisa de transplante de órgãos 9,14,15,16. As pesquisas com coração, iniciadas em 1989, mostraram que a talidomida, isolada ou em associação com a ciclosporina, prolongava a sobrevida de transplantes cardíacos heterotópicos ${ }^{9}$.

A literatura referente ao efeito da talidomida em aloenxertos de pele é controversa. Hellman et al.(1965) observaram que a talidomida retardou a rejeição de aloenxertos, principalmente quando estes haviam sido incubados com a droga ou quando os animais doadores, além dos receptores, também foram tratados com talidomida ${ }^{17}$. Vogelsang et al. (1988) relataram aumento na sobrevida de transplantes de pele com a administração da talidomida duas vezes ao dia ${ }^{10}$. Já Playfair et al.(1963) e Floersheim observaram aumento na sobrevida de aloenxertos de pele em animais tratados com esse medicamento ${ }^{18,19}$.

Vários trabalhos experimentais e clínicos já haviam mostrado que a ciclosporina prolonga a sobrevida de aloenxertos de pele ${ }^{6,16}$. No entanto, não foram encontrados na literatura relatos quanto ao efeito do diclofenaco em aloenxertos cutâneos. Neste trabalho, o diclofenaco foi introduzido como controle para avaliar os efeitos antiinflamatórios da talidomida. Cabe ressaltar o papel antiinflamatório pelo qual a talidomida destaca-se em relação a outros medicamentos , $^{8,17,18}$. Por este motivo, ela continua como medicamento de escolha em hanseníase. Por outro lado, existe ainda o efeito imunodepressor que pode associar-se na farmacocinética da talidomida e que não tem sido apontado em outros antiinflamatórios não-esteróides ${ }^{8,17,18}$. Neste sentido, coube a comparação entre talidomida e diclofenaco.

As doses dos medicamentos foram definidas com base em outros trabalhos experimentais em que a talidomida e a ciclosporina foram utilizadas como imunossupressoras ${ }^{7,8,16}$. No caso do diclofenaco, foi escolhida a dose diária máxima farmacologicamente recomendada. A administração dos medicamentos por meio de cateter orogástrico foi escolhida porque o método mostrou-se capaz de garantir a efetiva medicação dos animais em outros trabalhos experimentais 9 , 16 .

O presente trabalho mostrou que a talidomida, como droga isolada, prolongou a sobrevida dos aloenxertos, em relação ao grupo controle, em cerca de 24 horas, o que concorda com relatos anteriores 9 17. Estatisticamente, seu efeito foi comparável ao do antiinflamatório diclofenaco. Tal ação, pequena e transitória, poderia até ser esperada, pois Floersheim (1966) já havia publicado que várias drogas não imunossupressoras podem aumentar a sobrevida de aloenxertos em 30\% a 40\%, por mecanismos não específicos ${ }^{19}$. No caso da talidomida, pode-se destacar a redução da fagocitose e da quimiotaxia, reduzindo a resposta inflamatória no tecido transplantado ${ }^{19}$.

De acordo com Vogelsang et al. (1992), o nível plasmático de 5 $\mathrm{mg} / \mathrm{ml}$ de talidomida produz a resposta imunossupressora máxima na doença enxerto-contra-hospedeiro em transplantes de medula ós$\mathrm{sea}^{20}$. Doses de $200 \mathrm{mg}$ por via oral resultam em níveis médios de I,2 $\pm 0,2 \mathrm{mg} / \mathrm{m}^{20}$. Portanto, é admissível que doses maiores de talidomida possam prolongar por mais tempo a sobrevida dos aloenxertos.

O estudo da talidomida associada à ciclosporina para a profilaxia da rejeição de aloenxertos cutâneos parece ter sido testado apenas na linha de pesquisa à qual pertence este trabalho. A associação de talidomida com doses subterapêuticas de ciclosporina resultou em sobrevida do aloenxerto comparável à obtida com a dose habitual de ciclosporina utilizada em transplantes. Essa constatação reforça a possibilidade da talidomida atuar sinergicamente ou potencializar a função da ciclosporina. Outro efeito desejável desta associação é a redução do custo terapêutico e a provável diminuição de suas adversidades.

O padrão de rejeição observado nos grupos de animais tratados com ciclosporina já havia sido descrito por Hellmann et al. (1965) com o uso da talidomida em camundongos ${ }^{17}$. A necrose foi mais lenta em alguns animais, ocorrendo em focos, com persistência de ilhas de tecido viáveis. Não observamos este padrão com o uso isolado da talidomida, o que pode ser atribuído a um efeito espécie-específico.

Não foi possível a classificação da rejeiçãa em níveis de intensidade, como é feito, por exemplo, na rejeição cardíaca ${ }^{9}$, porque todos 
os enxertos foram biopsiados na fase de necrose total. A obtenção de biopsias seriadas dos aloenxertos antes da ocorrência de necrose poderia permitir esta classificação em cada animal, facilitando o estudo do efeito das drogas na reação inflamatória. Também não foram encontradas diferenças entre os grupos, em relação à fibrose dérmica e ao espessamento da camada íntima das artérias, que permitissem a caracterização do padrão histológico de rejeição crônica nos enxertos com maior sobrevida.

O processo de rejeição de aloenxertos de pele ocorre tanto por isquemia pela trombose e destruição dos vasos sangüíneos, como por destruição direta da epiderme e dos anexos da pele. A revisão da literatura mostrou que a realização dos enxertos nas orelhas de coelhos permite a obtenção de um leito receptor plano, sem irregularidades, graças à sua estrutura cartilaginosa, garantindo o total contato da pele transplantada com o leito receptor e sua integração 1,3 . Este fato foi confirmado no grupo controle com autoenxertos e que apresentaram 100\% de integração tecidual. Essa técnica prescinde de curativos, sendo possível a observação diária dos enxertos. Todos os enxertos foram realizados por um único pesquisador. Para que a observação fosse mais precisa, optou-se pelo registro do primeiro dia em que se observou sinais de rejeição e pelo registro do dia em que ocorreu a necrose total. Desta maneira, não houve a necessidade de calcular as porcentagens de pele viável e necrótica.

A associação entre o uso do diclofenaco e a eosinofilia no infiltrado inflamatório circunjacente ao aloenxerto necrosado foi um achado ocasional desta investigação. Revisão da literatura não mostrou outros relatos associando o uso do diclofenaco à intensificação da eosinofilia na doença do enxerto-contra-hospedeiro'l. A eosinofilia tecidual é dependente da produção de IL-5 e de IL-4 pelos linfócitos T auxiliares tipo 2. A IL-4, além de promover a produção da IL-5, também participa do recrutamento tecidual dos eosinófilos, induzindo à produção de eotaxina pela pele. A maioria das manifestações fisiopatológicas de pacientes alérgicos são atribuídas direta ou indiretamente à produção de IL-4 e IL-5. Contudo, a eosinofilia pode ocorrer na ausência de mRNA de IL-5, por vias alternativas. 0 IFN-gama inibe a produção de IL-5, provavelmente atuando na função das células T auxiliares tipo 222,23.

Embora a ciclosporina reduza a produção de IFN-gama, ela inibe a expressão de IL-524. Esse paradoxo refletiu-se no encontro de maior ou menor eosinofilia nos grupos tratados com diferentes doses do medicamento, em relação ao grupo controle, sugerindo mecanismos de ação diversos e dose-dependentes. Por outro lado, a ação da talidomida na produção de IFN-gama não está bem estabelecida, sendo descrito aumento e redução nos níveis desta citocina. Verificou-se que a talidomida apresenta efeitos dicotômicos e opostos na modulação de citocinas, dependendo do tipo de célula alvo e das vias de ativação celular ${ }^{25}$. No presente estudo, foi observado que a associação de talidomida com ciclosporina levou à redução da concentração de eosinófilos teciduais e maior sobrevida dos enxertos. A associação entre menor eosinofilia e maior sobrevida de transplantes já foi verificada anteriormente ${ }^{2 !}$.

Este trabalho mostra que drogas com efeito imunodepressor pequeno em uso isolado podem ser bons imunossupressores quando combinadas a outros medicamentos, como foi enfatizado em relação à talidomida nesta linha de pesquisa. Os resultados apresentados estimulam a pesquisa destas associações medicamentosas, que trazem novas perspectivas nos transplantes em geral. Seria interessante estudar o efeito do diclofenaco associado à ciclosporina, pois os resultados apresentados sugerem a presença de atividade imunorreguladora deste antiinflamatório.

O melhor conhecimento das complexas interações entre citocinas e das diversas vias de ativação celular permitirá o desenvolvimento de drogas mais específicas e potentes, com menos efeitos adversos.

\section{ConClusões}

A talidomida associada a doses subterapêuticas de ciclosporina foi tão eficaz quanto a ciclosporina em doses terapêuticas na preservação de aloenxertos cutâneos em coelhos. A talidomida e o diclofenaco utilizados isoladamente foram pouco eficazes para manter a sobrevida de aloenxertos cutâneos em coelhos.

O uso do diclofenaco e da ciclosporina em doses subterapêuticas associou-se a maior eosinofilia no infiltrado inflamatório circunjacente ao aloenxerto de pele necrosado, enquanto a talidomida junto com ciclosporina acompanhou-se de menor eosinofilia local. Portanto, é pertinente supor que a combinação da talidomida com doses subterapêuticas de ciclosporina possa ser suficiente para manter a vitalidade de aloenxertos de pele em coelhos.

\section{Agradecimentos}

Os autores agradecem ao CNPq e FAPEMIG os auxílios financeiros que permitiram a realização do presente trabalho.

\section{Conflito de interesse: não há}

\section{SUMMARY}

ASSESSMENT OF IMMUNOSSUPRESION INDUCED BY THALIDOMIDE, CYCLOSPORINE AND DICLOFENAC ON SKIN ALLOGRAFT SURVIVAL IN RABBITS

OBJECTIVE. Allografting is one of the therapeutic alternatives for extensive burn victims without sufficient skin donor areas. This research studied the effects of cyclosporine, as an immunosuppressor model, and thalidomide and dyclofenac as anti-inflammatory drugs on an experimental skin allograft research.

METHODS. Forty-two rabbits were divided in the following groups $(n=6)$ : Group I - autografting control; Group 2 - allografting control; Group 3 - allografts under thalidomide effect ( $100 \mathrm{mg} / \mathrm{kg} /$ day); Group 4 - allografts under sodium dyclofenac effect (2 mg/kg/day); - Group 5 allografts under cyclosporine effect $(10 \mathrm{mg} / \mathrm{kg} / \mathrm{day})$; Group 6 - allografts under cyclosporine effect (5 mg/kg/day); Group 7- allografts under cyclosporine (5 mg/kg/day) plus thalidomide ( $100 \mathrm{mg} / \mathrm{kg} /$ day) effect. Drugs were given via orogastric tube since the day before transplantation and daily during the postoperative period. Circular total skin grafts of the ear were exchanged between California and White New Zealand rabbits. 
RESULTS. Cyclosporine $10 \mathrm{mg} / \mathrm{kg} /$ day increased allograft survival and this effect was comparable to the association of cyclosporine $5 \mathrm{mg} / \mathrm{kg} /$ day with thalidomide $100 \mathrm{mg} / \mathrm{kg} /$ day. Thalidomide as an isolated drug and dyclofenac had a minimum effect on the average survival of the skin allografts. The number of eosinophils around the necrotic skin was higher in the dyclofenac group and lower in the group receiving cyclosporine associated with thalidomide.

CONCLUSION. This study showed that thalidomide may be an useful drug when associated with subtherapeutic doses of cyclosporine for treatment of skin allografts. [Rev Assoc Med Bras 2008; 54(I): 42-7]

KEY WORDS: Thalidomide. Cyclosporin. Dyclofenac. Skin Allograft.

\section{REFERÊNCIAS}

I. Coruh A, Tosun Z, Ozbebit U.Close relative intermingled skin allograft and autograft use in the treatment of major burns in adults and children. J Burn Care Rehabil. 2005,26:47 I-7.

2. Wang YB, Kusumoto K, Kakudo N, Ogawa Y. he use of skin allograft with donor-specific tolerance in a rabbit model of full-thickness burn. Burns. 2006,32:737-43.

3. Koller J, Orsag M.Skin grafting options at the Burn and Reconstructive Surgery Department of the Faculty Hospital in Bratislava. Acta Chir Plast. 2006,48:65-71.

4. Elias BG, Meunier DI, Squifflet JP, Marot L, Weynand B, VanWijck RR, et al. Immunologic tolerance to skin allograft after graft-versus-host disease. Plast Reconstr Surg. 2007, 1 19:40e-4e.

5. Earle SA, El-Haddad A, Patel MB, Ruiz P, Pham SM, Majetschak M. Prolongation of skin graft survival by exogenous ubiquitin. Transplantation. 2006;82: 1544-6.

6. Mindikoglu AN, Cetinkale O. Prolonged allograft survival in a patient with extensive burns using cyclosporin. Burns. 1993; 19:70-2.

7. Eldad A, Benmeir P, Weinberg A, Neuman A, Chaout M, Ben-Bassat $H$, et al. Cyclosporin A treatment failed to extend skin allograft survival in two burn patients. Burns. 1994;20:262-4.

8. Tamura F, Vogelsang GB, Reitz BA, Baumgartner Wa, Herskowitz A. Combination thalidomide and cyclosporine for cardiac allograft rejection. Transplantation. 1990;49:20-5.

9. Carvalho JBV, Petroianu A, Alberti LR. Effects of immunosuppresion induced by thalidomide and cyclosporine in heterotopic heart transplantation in rabbits. Transpl Proc. 2007;39: 1640-41.
10. Vogelsang GB, Hess AD, Santos GW. Thalidomide for treatment of graftversus-host disease. Bone Marrow Transplant. 1988:3:393-8.

1।. Laffitte E. The revival of thalidomide: an old drug with new indications. Rev Prat. 2006;56: 1977-83.

12. Van den Akker JM, Hene RJ, Hoitsma AJ. Inferior results with basis immunosuppression with sirolimus in kidney transplantation. Neth J Med. 2007; 65:23-8

13. Petroianu A. Pesquisa experimental. In: Petroianu A. Ética, moral e deontologia médicas. Rio de Janeiro: Guanabara Koogan; 2000. p. I 85-90.

14. Petroianu A. Interposição traqueal na reconstrução do esôfago cervical de cão. Rev Col Bras Cir. 1992, 19:156-9.

15. Petroianu A. Transplante intestinal. Rev Cir Hosp Mater Dei. I 988, I I I-2.

16. Petroianu A, Vasconcellos LS, Alberti LR, Castro LPF, Leite JMB. Natural pregnancy in rabbits that underwent oophorectomy and orthotopic allogeneic or autologous ovarian transplantation. Fertil Steril. 2002;77:1298-9.

17. Hellmann K, Duke DI, Tucker DF. Prolongation of skin homograft survival by thalidomide. Br Med J. 1965;2:687-9.

18. Playfair JHL, Leuchars E, Davies AJS. Effect of thalidomide on skin graft survival. Lancet. 1963; 1: 1003-4.

19. Floersheim GL. Another chance for thalidomide. Lancet. 1966; I:207.

20. Voegelsang GB, Farmer ER, Hess AD, Altamonte V, Beschorner WE, Jabs DA, et al. Thalidomide for the treatment of chronic graft-versus-host disease. N Engl J Med. 1992;326: 1055-8.

21. Lee A, Cooper M, Craig J, Knight J, Keneally J. Effects of nonsteroidal antiinflammatory drugs on postoperative renal function in adults with normal renal function. Cochrane Database Syst Rev. 2007, I 8:CD002765.

22. Le Moine A, Flamand V, Demoor FX, Noel JC, Surquin M, Kiss R, et al. Critical roles for IL-4, IL-5, and eosinophils in chronic skin allograft rejection. J Clin Invest. 1999; 103:1 659-67.

23. Gutting BW, Updyke LW, Amacher DE. Diclofenac activates T cells in the direct popliteal lymph node assay and selectively induces $\lg G$ and $\lg E$ against co-injected TNP-OVA. Toxicol Lett. 2002; 131:167-80.

24. Martinez OM, Ascher NL, Ferrell L, Villanueva J, Lake J, Roberts JP, et al. Evidence for a nonclassical pathway of graft rejection involving interleukin 5 and eosinophils. Transplantation. 1993;55:909- 18.

25. Corral LG, Kaplan G. Immunomodulation by thalidomide and thalidomide analogues. Ann Rheum Dis. 1999;58(Suppl I): I07-II3.

Artigo recebido: 28/04/07 Aceito para publicação: 18/09/07 